University at Albany, State University of New York

Scholars Archive

\title{
The Effects of Revictimization on Coping and Depression in Women Sexual Assault Victims
}

\author{
Cynthia J. Najdowski \\ University at Albany, State University of New York, cnajdowski@albany.edu \\ Sarah E. Ullman \\ The University of Illinois at Chicago
}

The University at Albany community has made this article openly available. Please share how this access benefits you.

Follow this and additional works at: https://scholarsarchive.library.albany.edu/psychology_fac_scholar

Part of the Clinical Psychology Commons, Counseling Commons, Counseling Psychology Commons, Criminology and Criminal Justice Commons, Domestic and Intimate Partner Violence Commons, Family, Life Course, and Society Commons, and the Social Psychology Commons

\section{Recommended Citation}

Najdowski, C. J., \& Ullman, S. E. (2011). The effects of revictimization on coping and depression in female sexual assault victims. Journal of Traumatic Stress, 24, 218-221. DOI: 10.1002/jts.20610

This Article is brought to you for free and open access by the Psychology at Scholars Archive. It has been accepted for inclusion in Psychology Faculty Scholarship by an authorized administrator of Scholars Archive.

Please see Terms of Use. For more information, please contact scholarsarchive@albany.edu. 


\title{
PRE-PRINT. This paper is not the copy of record and may not exactly replicate the authoritative document published in the journal.
}

Running head: REVICTIMIZATION, COPING, AND DEPRESSION

Word count: 2,455

The Effects of Revictimization on Coping and Depression in Women Sexual Assault Victims

\author{
Cynthia J. Najdowski ${ }^{1}$
}

Sarah E. Ullman ${ }^{1}$

Acknowledgments. This research was supported by the National Institute on Alcohol Abuse and Alcoholism grant R01 \#13445 to Sarah E. Ullman. We acknowledge Henrietta Filipas, Stephanie Townsend, Laura Starzynski, and Kelly Kinnison for assistance with data collection.

Correspondence should be addressed to

During review, Cynthia J. Najdowski:

Department of Psychology

University of Illinois at Chicago

Behavioral Sciences Building 1007 West Harrison Street (M/C 285)

Chicago, Illinois 60607-7140

\author{
After publication, \\ Sarah E. Ullman: \\ Department of Criminology, Law, and Justice \\ University of Illinois at Chicago \\ Behavioral Sciences Building \\ 1007 West Harrison Street (M/C 141) \\ Chicago, Illinois - 60607-7140
}

\footnotetext{
${ }^{1}$ Department of Criminology, Law, and Justice; University of Illinois at Chicago; Chicago, Illinois
} 
Phone: 312-996-3036

Fax: 312-413-4122

cnajdo2@uic.edu
Phone : 312-996-5290

Fax: 312-996-8355

seullman@uic.edu 


\begin{abstract}
On two mail surveys completed 1 year apart, 555 women reported their experiences of sexual assault, the strategies they used to cope with those experiences, and feelings of depression. Path analyses controlling for baseline coping and depression revealed that victims who were revictimized during the study reported using more maladaptive and adaptive coping strategies than did victims who were not revictimized. Further, women who were revictimized reported more depression than others. This effect was explained in part by revictimized women's increased maladaptive coping. Implications for understanding coping and recovery in women who experience multiple sexual assaults in adulthood are discussed.

Keywords: Coping; Depression; Sexual abuse/assault, adulthood; Path Analysis; Women
\end{abstract}




\section{The Effects of Revictimization on Coping and Depression in Women Sexual Assault Victims}

Approximately $20 \%$ of women are sexually assaulted during their lives (Post, in press), and women who have been victimized are at increased risk of experiencing further sexual victimization (Livingston, Testa, \& VanZile-Tamsen, 2007). Longitudinal research suggests that using maladaptive coping (i.e., strategies that alleviate distress without actually addressing the source of distress itself) to deal with assault-related distress might contribute to revictimization risk. For instance, victims who attempt to cope with PTSD symptoms by using sex, alcohol, and/or drugs are more likely than others to experience further assault (e.g., Messman-Moore, Ward, \& Brown, 2009; Ullman, Najdowski, \& Filipas, 2009, which used data from the same sample reported on herein), perhaps because they are more likely to encounter potential perpetrators and/or less able to detect or respond to risk appropriately (Messman-Moore \& Brown, 2006).

Sexual assault revictimization might, in turn, increase maladaptive coping. In one of the few studies to examine how cumulative victimization experiences affect current coping strategies, Filipas and Ullman's (2006) cross-sectional research showed that college women who experienced sexual assault were more likely to engage in maladaptive coping strategies (i.e., acting out sexually, drinking to cope, self-blaming, withdrawing from others) if they had also experienced childhood sexual abuse than if they had not. Yet, we know of no research that has examined how women cope with experiencing multiple sexual assaults in adulthood. Thus, we conducted a longitudinal study of community women who were sexually assaulted as adults. We predicted that those who experienced another assault during a 1-year follow-up period would use more maladaptive coping strategies than would other victims. 
In addition, cross-sectional analyses of the current data revealed that a history of more traumatic life events, including childhood sexual abuse, related to greater maladaptive and adaptive coping in sexual assault victims (Najdowski \& Ullman, 2009b), perhaps because experiencing cumulative traumas creates a greater need to cope using any means possible. Thus, we also assessed adult sexual assault victims' adaptive coping (i.e., strategies that focus on dealing directly with the source of distress), predicting that victims who were revictimized during the study would also use more adaptive coping strategies compared to other victims.

What are the consequences of revictimized victims' increased maladaptive and adaptive coping efforts? Women victims of sexual assault who engage in maladaptive coping have been shown to have poorer outcomes than others. For instance, Filipas and Ullman (2006) found that college women who used more maladaptive coping strategies had more PTSD symptoms. Other studies (e.g., Gutner, Rizvi, Monson, \& Resick, 2006), including two using cross-sectional data from the current sample (Najdowski \& Ullman, 2009b; Ullman, Townsend, Filipas, \& Starzynski, 2007), also indicate that maladaptive coping strategies (e.g., behavioral disengagement, denial, self-distraction, drinking to cope) negatively affect victims' recovery. In fact, longitudinal research using data from the same sample reported on herein revealed that women who experienced sexual assault more than once as adults reported significantly worse PTSD and problem drinking compared to other victims, even after controlling for baseline symptomatology (Najdowski \& Ullman, 2009a). Thus, we expected that, because of their greater use of maladaptive coping, revictimized victims would experience greater depression than other victims.

Adaptive coping has less clear effects on recovery, however. Cross-sectional analyses of the sample used herein revealed that both maladaptive and adaptive coping mediated the positive 
effect of cumulative traumas on current PTSD symptoms (Najdowski \& Ullman, 2009b), consistent with other research linking adaptive coping to distress (e.g., Brand \& Alexander, 2003). Yet Gutner et al. (2006) found that increases in adaptive coping (i.e., cognitive restructuring, expressed emotion, social support coping strategies) related to less severe PTSD after 3 months in women victims of sexual and physical assault. Still, Littleton, Horsley, John, and Helson's (2007) meta-analysis revealed no effects of adaptive coping on adjustment among abuse victims. Thus, we did not have a specific hypothesis about the effect of adaptive coping on depression in women victims of sexual assault over 1 year, nor whether adaptive coping would be associated with increased or decreased depression in revictimized victims compared to other victims.

\section{Method}

\section{Participants and Procedure}

Advertisements in newspapers and fliers distributed throughout the Chicago area invited women aged 18 or older with unwanted sexual experiences since age 14 to participate in a confidential mail survey. Interested women were mailed the Time 1 (T1) survey with a cover letter, informed consent form, a list of community resources for survivors of violence, and a postcard to return if they were interested in participating in the Time 2 (T2) survey. 1,084 women completed the T1 survey (a 90\% response rate), and 909 expressed interest in completing the T2 survey. Approximately 1 year later, women were mailed the second survey with an updated list of community resources. Women received $\$ 20$ for completing each survey. T2 surveys were returned by 625 women - a $69 \%$ response rate. Seventy women did not experience sexual assault as it was assessed herein and were not included in our analyses. Thus, the final sample included 555 women who reported a sexual assault experience at T1 and who completed 
both surveys. The sample was ethnically diverse (46\% African American, 39\% Caucasian, 6\% Hispanic/Latina, $2 \%$ Asian, and 7\% other), and women were 18 to 68 years old $(M=33, S D=$ 11). Women were treated in accordance with our university's ethical guidelines.

\section{Measures}

Sexual victimization. Sexual assault and revictimization were each assessed dichotomously (experienced, not experienced) using the Sexual Experiences Survey (SES; Koss \& Gidycz, 1985). At T1, the SES assessed sexual assault, defined as completed rape, attempted rape, sexual coercion, or unwanted sexual contact at age 14 years or older. All women in this sample had experienced a sexual assault according to these guidelines. At T2, the SES revealed that 248 women (45\%) had experienced another sexual assault since the last survey. Women's victimization experiences were heterogeneous, but most involved completed rape.

Coping strategies. At both T1 and T2, participants completed the Brief COPE, a 28-item self-report scale of coping strategies (Carver, Scheier, \& Weintraub, 1989). Strategies used in the past 30 days to cope with the assault were assessed on a scale ranging from 1 (I didn't do this at all) to 4 (I did this a lot). Maladaptive coping was computed as the average of responses to 12 items composing the behavioral disengagement, denial, humor, self-blame, self-distraction, and substance use subscales (T1 $\alpha=.83, M$ inter-item correlation $=.28 ; \mathrm{T} 2 \alpha=.84, M$ inter-item correlation $=.30$ ). Adaptive coping was computed as the average of 16 items composing the acceptance, active coping, emotional support, instrumental support, planning, positive reframing, religion, and venting subscales $(\mathrm{T} 1 \alpha=.89, M$ inter-item correlation $=.33$; $\mathrm{T} 2 \alpha=.90, M$ interitem correlation $=.36$ )

Depression. Depression was assessed at both T1 and T2 using 7 items from the CES-D10 (Andresen, Carter, Malmgren, \& Patrick, 1994). Using a 4-point scale, ranging from 0 (none 
of the time or rarely) to 3 (most or all of the time), participants rated how often they had felt as described by each item during the past 30 days. Responses were averaged to compute a reliable scale $(\mathrm{T} 1 \alpha=.84, M$ inter-item correlation $=.44 ; \mathrm{T} 2 \alpha=.88, M$ inter-item correlation $=.52)$.

\section{Results}

Victims who completed only the T1 survey did not differ significantly in ethnicity, age, T1 maladaptive coping, T1 adaptive coping, or T1 depression from victims who completed both surveys, all $t \mathrm{~s}(925-963)=-1.87-1.75, n s ; \chi^{2}(7,959)=7.75, n s$.

To test the effects of revictimization on coping and depression, we conducted an observed variables path analysis with a structural equation modeling framework using maximum likelihood estimation. T1 measures of coping and depression were included as control variables. Due to having missing data, 33 participants were excluded from the analysis. Based on significant correlations, T1 maladaptive coping, T1 adaptive coping, and T1 depression were allowed to covary with each other, as were T2 maladpative coping and T2 adaptive coping. Paths representing these associations are not discussed, however.

We first tested the saturated model, which included all possible direct and indirect effects. We dropped 7 nonsignificant (i.e., $p>.05$ ) paths from (a) T1 depression to revictimization; (b) T1 maladaptive coping to T2 adaptive coping and T2 depression; (b) T1 adaptive coping to revictimization, T2 maladaptive coping, and T2 depression; and (c) T2 adaptive coping to $\mathrm{T} 2$ depression. These modifications resulted in a good model fit, $\chi^{2}(7,522)=$ 11.30, $n s, \mathrm{CFI}=1.00, \mathrm{RMSEA}=.03$. (See Figure 1 for the final model with standardized beta weights.) T1 maladaptive coping was the only significant predictor of revictimization over 1 year. T1 depression significantly increased both maladaptive and adaptive coping efforts at T2. Revictimization also related to significantly greater coping of both kinds at $\mathrm{T} 2$, as well as 
significantly more depression at $\mathrm{T} 2$. The association between revictimization and $\mathrm{T} 2$ depression was partially mediated by maladaptive (but not adaptive) coping.

\section{Discussion}

Of note, $45 \%$ of women sexual assault victims were revictimized during the course of the study. Although this rate might seem high, we followed women for 1 year, a longer time frame than used in other studies reporting lower revictimization rates (e.g., Messman-Moore \& Brown, 2006). Also, whereas most research on factors related to sexual assault has studied college women, we studied community women who are, in general, older and more poorly functioning. For example, many of our participants were at risk for revictimization not only because of past sexual assault experiences, but also because they were experiencing significant distress (e.g., PTSD) and engaging in problem drinking (Najdowski \& Ullman, 2009a). Further, our definition of sexual assault captured a broader sample of experiences than only completed rape, including attempted rape, sexual coercion, and unwanted sexual contact.

Consistent with past research (e.g., Messman-Moore et al., 2009; Ullman et al., 2009), women victims who used more maladaptive coping strategies were more likely than others to be revictimized over the course of the 1-year study. For the first time, however, we also showed that experiencing multiple sexual assaults in adulthood was related to increased use of both maladaptive and adaptive coping efforts. In addition, women who were revictimized reported more depression than others. This effect was explained in part by revictimized women's increased maladaptive coping. These results suggest that victims, particularly those who are revictimized, are engaging in multiple strategies to cope with their assault experiences. Thus, research should focus on developing interventions to improve victims' coping and, thereby, recovery. Further, given that revictimized women experienced more depression despite engaging 
in adaptive coping strategies, future studies should seek to understand why women's adaptive coping efforts are failing.

Although our results are consistent with the hypothesis that revictimized victims experience worse outcomes because they are coping more poorly, it remains possible that revictimization increases distress and, in turn, the need to cope by any means. In fact, experiencing more depression at $\mathrm{T} 1$ was associated with increased coping at $\mathrm{T} 2$, including both maladaptive and adaptive efforts. Thus, longer-term research is needed to test whether coping increases distress or vice versa.

In summary, this study represents an important first step in understanding how women cope with and recover from experiencing multiple sexual assaults in adulthood. Our results are consistent with a growing body of research showing that all of women's traumatic experiences must be taken into consideration to fully understand how sexual assault influences women's coping and recovery (e.g., Najdowski \& Ullman, 2009a; 2009b). 


\section{References}

Andresen, E. M., Carter, W. B., Malmgren, J. A., \& Patrick, D. L. (1994). Screening for depression in well older adults: Evaluation of a short form of the CES-D. American Journal of Preventive Medicine, 10, 77-84.

Brand, B. L., \& Alexander, P. C. (2003). Coping with incest: The relationship between recollections of childhood coping and adult functioning in female survivors of incest. Journal of Traumatic Stress, 16, 285-293.

Carver, C. S., Scheier, M. F., \&Weintraub, J. K. (1989). Assessing coping strategies: A theoretically based approach. Journal of Personality and Social Psychology, 56, 267-283.

Filipas, H. H., \& Ullman, S. E. (2006). Child sexual abuse, coping responses, self-blame, posttraumatic stress disorder, and adult sexual revictimization. Journal of Interpersonal Violence, 21, 652-672.

Gutner, C. A., Rizvi, S. L., Monson, C. M., \& Resick, P. A. (2006). Changes in coping strategies, relationship to the perpetrator, and posttraumatic distress in female crime victims. Journal of Traumatic Stress, 19, 813-823.

Koss, M. P., \& Gidycz, C. A. (1985). The sexual experiences survey: Reliability and validity. Journal of Consulting and Clinical Psychology, 53, 442-443.

Littleton, H., Horseley, S., John, S., \& Nelson, D. V. (2007). Trauma coping strategies and psychological distress: A meta-analysis. Journal of Traumatic Stress, 20, 977-988.

Livingston, J.A., Testa, M., \& VanZile-Tamsen, C. (2007). The reciprocal relationship between sexual victimization and sexual assertiveness. Violence Against Women, 13, 1-16. 
Messman-Moore, T. L., \& Brown, A. L. (2006). Risk perception, rape, and sexual revictimization: A prospective study of college women. Psychology of Women Quarterly, $30,159-172$.

Messman-Moore, T. L., Ward, R. M., \& Brown, A. L. (2009). Substance use and PTSD symptoms impact the likelihood of rape and revictimization in college women. Journal of Interpersonal Violence, 24, 499-521.

Najdowski, C. J., \& Ullman, S. E. (2009a). Prospective effects of sexual victimization on PTSD and problem drinking. Addictive Behaviors, 34, 965-968.

Najdowski, C. J., \& Ullman, S. E. (2009b). PTSD and self-rated recovery among adult sexual assault survivors: The effects of traumatic life events and psychosocial variables. Psychology of Women Quarterly, 33, 43-53.

Post, L. A. (in press). Sexual violence prevalence. In J. White \& M. Koss (Eds.), Violence against women and children. Washington, DC: American Psychological Association.

Ullman, S. E., Najdowski, C. J., \& Filipas, H. H. (2009). Child sexual abuse, post-traumatic stress disorder, and substance use: Predictors of revictimization in adult sexual assault survivors. Journal of Child Sexual Abuse, 18, 367-385.

Ullman, S. E., Townsend, S. M., Filipas, H. H., \& Starzynski, L. L. (2007). Structural models of the relations of assault severity, social support, avoidance coping, self-blame, and PTSD among sexual assault survivors. Psychology of Women Quarterly, 31, 23-37. 
Table 1

Bivariate correlations between revictimization, coping, and depression ( $n s=527-551)$.

\begin{tabular}{|c|c|c|c|c|c|c|c|}
\hline & 1. & 2. & 3. & 4. & 5. & 6. & 7. \\
\hline 1. Revictimization & - & $.18 * * *$ & .02 & $.13 * *$ & $.19 * * *$ & $.14 * * *$ & $.22 * * *$ \\
\hline 2. T1 Maladaptive coping & & - & $.39 * * *$ & $.39 * * *$ & $.49 * * *$ & $.20 * * *$ & $.30 * * *$ \\
\hline 3. T1 Adaptive coping & & & - & $.12 * *$ & $.19 * * *$ & $.48 * * *$ & .06 \\
\hline 4. T1 Depression & & & & - & $.35 * * *$ & $.14 * * *$ & $.54 * * *$ \\
\hline 5. T2 Maladaptive coping & & & & & - & $.43 * * *$ & $.49 * * *$ \\
\hline 6. T2 Adaptive coping & & & & & & - & $.23^{* * *}$ \\
\hline 7. T2 Depression & & & & & & & - \\
\hline
\end{tabular}

Note. $* * p \leq .01$ and $* * * p \leq .001$. 


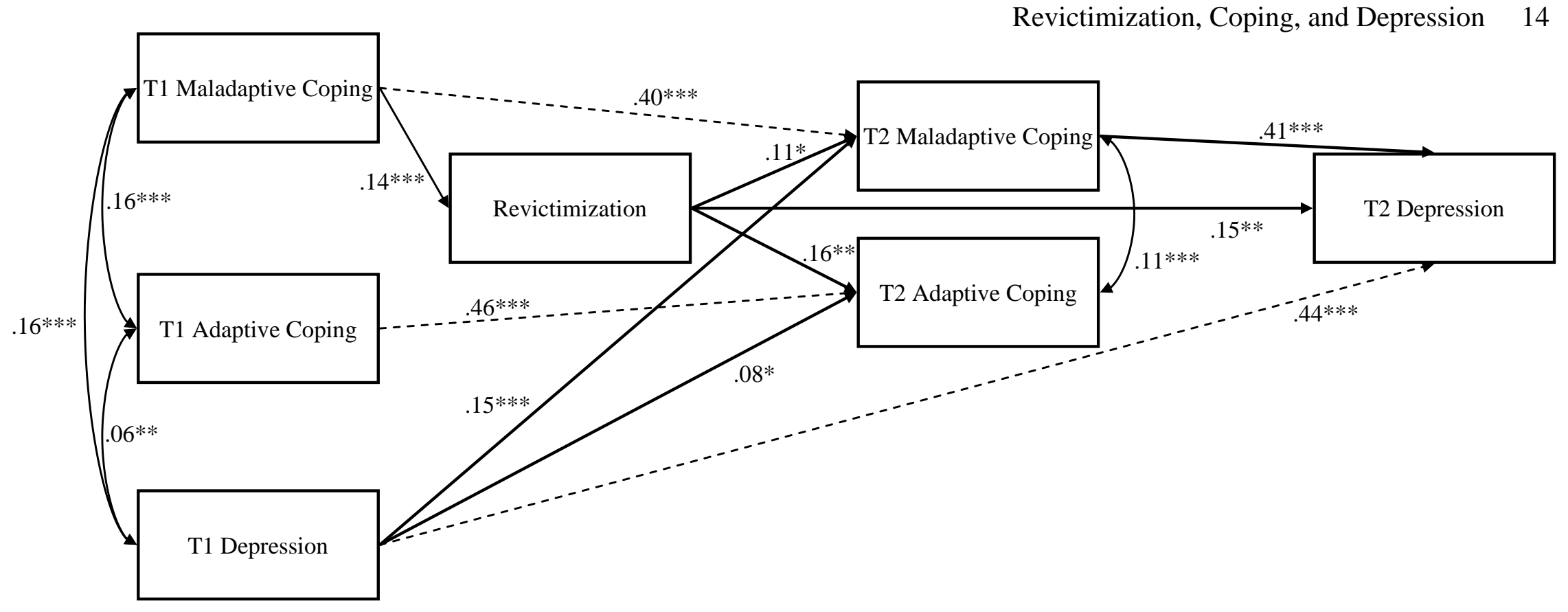

Figure 1. Final model of relations among revictimization, coping, and depression.

Note. $* p \leq .05, * * p \leq .01$, and *** $\mathrm{p} \leq .001$. "T1" refers to Time 1 and "T2" refers to Time 2. Dashed lines represent control variables and their effects. 